\title{
Vastidão de os Seis Pequenos Quadros (1981) de Bruno Kiefer: um estudo sobre sua estrutura intervalar, gestos musicais e possíveis relações com outras composições do autor
}

\author{
Germano Gastal Mayer (Universidade Federal de Pelotas, Pelotas, RS) \\ germano@mayer.art.br
}

Any Raquel Carvalho (Universidade Federal do Rio Grande do Sul, Porto Alegre, RS) anyraque@cpovo.net

Resumo: 0 presente trabalho oferece uma análise dos gestos musicais e configurações intervalares da peça intitulada Vastidão, pertencente aos Seis Pequenos Quadros (1981) para piano de Bruno Kiefer. A incidência constante de gestos previamente levantados por Luciane CARDASSI (1998) em outras obras de Kiefer bem como a presença do elemento octatônico são estudados e inter-relacionados com obras precedentes do compositor. A teoria dos conjuntos de Allan Forte é utilizada aqui como base teórica. A densidade gestual encontrada nesta composição de data tardia em meio ao conjunto de obras para piano do autor e sua curta duração apontam para uma síntese estilística.

Palavras-chave: Bruno Kiefer, gestos musicais, teoria dos conjuntos, análise.

Vastidão [Vastness] of Seis Pequenos Quadros [Six Small Pictures] (1981) by Bruno Kiefer: a study of its intervallic structure, musical gestures and possible relationships with other works by the composer

Abstract: The present article offers an analysis of the musical gestures and intervallic configurations of the composition Vastidão [Vastness], which belongs to the set entitled Seis Pequenos Quadros [Six Small Pictures] (1981) for piano by Brazilian composer Bruno Kiefer. The recurring musical gestures from other of Kiefer's compositions, previously surveyed by Luciane CARDASSI (1998), as well as the presence of octatonic elements, are studied and related to preceding Kiefer's works. Set theory by Allan Forte is applied here as a theoretical basis. The density of the gestures observed in this late piece, and its brevity, point to a stylistic synthesis.

Keywords: Bruno Kiefer, musical gestures, set theory, analysis.

1 - Introdução

0 compositor, escritor e professor Bruno Kiefer (19271987) formou-se em química, física e flauta transversal na Universidade Federal do Rio Grande do Sul, instituição na qual também lecionou e participou da implantação do Programa de Pós-Graduação em Música (1987). Tendo estudado harmonia e contraponto com Ênio Freitas de Castro, a música para piano teve fundamental importância na sua produção.
0 presente artigo é um recorte de pesquisa que teve por objetivo a investigação dos Seis Pequenos Quadros (1981) para piano de Bruno Kiefer. ${ }^{1}$ Neste artigo é oferecida uma análise do $1^{\circ}$ Quadro, intitulado Vastidão, o qual concentra uma significativa quantidade de gestos musicais idiossincráticos do compositor, além de configurações intervalares existentes também em outras obras do autor. 
0 conjunto de peças intitulado Seis Pequenos Quadros (1981) foi encomendado por Aymara Célia para a comemoração do aniversário de quarenta anos de seu marido, o médico psiquiatra e músico que residia em Porto Alegre, Rafael Célia. Trata-se de seis miniaturas musicais pertencentes ao último período composicional de Kiefer. Quando compôs esta coleção o compositor já havia atingido sua plena maturidade artística, alcançada por volta de 1970. Nas palavras de Chaves, este criador estava "liberto do afã da pesquisa e da busca pela afirmação pessoal... revelando um compositor mais solto, não raro mais bemhumorado" (CHAVES, 1995, s/p).

A análise proposta toma como pressupostos teóricos os gestos musicais organizados e sistematizados por Luciane CARDASSI (1998), os quais transitam por, pelo menos, vinte e uma obras compostas entre 1970 e 1983. Estas obras, selecionadas em sua tese de mestrado a partir das temáticas "terra", "vento" e "horizonte" (fato que exclui a peça objeto deste estudo), foram relacionadas à poesia de Carlos Nejar. A autora organizou, nomeou e agrupou todos os gestos musicais em famílias. Estes gestos considerados como "de autocitação", constituem uma das características mais marcantes do estilo do compositor (CARDASSI, 1998, p.176).

Escritos em 1981, os Seis Pequenos Quadros inserem-se no periodo em que foram compostas as obras analisadas por CARDASSI, sendo que das seis peças, o Quadro n'. 1, Vastidão, é o que apresenta a maior gama de gestos musicais levantados. Em sua pequena dimensão temporal concentra características gerais de seu estilo pianístico, no que parece ser uma sintese de aspectos recorrentes de sua obra. Um indício para este julgamento é a proxi- midade de temática em relação à Terra Selvagem (1971), obra em que "o estilo instrumental de Bruno Kiefer está exposto à perfeição" (CHAVES, 1992, s/p). 0 levantamento e a contextualização dos gestos musicais ${ }^{2}$ encontrados em Vastidão em meio à sua estrutura e outras composições prévias projetam nova luz sobre esta peça. Além de caracterizarem a linguagem musical utilizada, situam a composição no contexto estético de Kiefer.

\section{2 - Análise dos Seis Pequenos Quadros de Bruno Kiefer}

A partir da constatação superficial de elementos octatônicos em Vastidão, ${ }^{3}$ optou-se pela investigação da organização de suas alturas no intuito de apurar uma possível constante nas relações intervalares que contribuísse para a coesão do discurso. Com este fim, aplicou-se a teoria dos conjuntos de Allen FORTE (1973).

A presente análise estrutura-se nas seguintes etapas:

- Delimitação das estruturas formais e gestuais de Vastidão;

- Análise dos parâmetros textura, ritmo e dinâmica para verificar como estes elementos se interrelacionam com a estrutura da peça, tomando como unidades básicas os gestos musicais;

- Análise do conteúdo intervalar através da teoria dos conjuntos para constatar a recorrência de padrões;

- Organização e sistematização dos dados.

0 Ex.1 localiza as seções da peça estabelecidas a partir de alguns gestos musicais de referência:

\begin{tabular}{|c|c|c|c|c|c|}
\hline Seções & \multicolumn{3}{|c|}{$\begin{array}{c}\text { Localização das Seções e } \\
\text { Gestos Musicais por compasso }\end{array}$} & \multicolumn{2}{|c|}{ Gestos Musicais } \\
\hline \multirow{5}{*}{ A } & \multirow{5}{*}{ c. $1-12$} & \multicolumn{2}{|c|}{ anacruse ao c. $1-2$} & \multicolumn{2}{|c|}{$1^{\circ}$ tema da chamada } \\
\hline & & \multicolumn{2}{|c|}{ anacruse ao c. $3-5$} & \multicolumn{2}{|c|}{$2^{\circ}$ tema da chamada } \\
\hline & & \multicolumn{2}{|c|}{ anacruse ao c. $6-7$} & \multicolumn{2}{|c|}{$3^{\circ}$ tema da chamada } \\
\hline & & \multirow{2}{*}{ anacruse ao c. 8-12 } & Anacruse ao c. 8 & $4^{\circ}$ tema da chamada & \multirow{2}{*}{$\begin{array}{l}\text { trilha } \\
\text { melódico }\end{array}$} \\
\hline & & & c. 10 & golpe rítmico & \\
\hline \multirow{5}{*}{ B } & \multirow{5}{*}{ c. $13-33$} & \multicolumn{2}{|c|}{ c. 14} & tema contrapontístico & \multirow{5}{*}{$\begin{array}{c}\text { trilha } \\
\text { melódica }\end{array}$} \\
\hline & & \multicolumn{2}{|c|}{ c. 23} & tema contrapontístico & \\
\hline & & \multicolumn{2}{|c|}{ c. 28} & tema contrapontístico & \\
\hline & & \multicolumn{2}{|c|}{ c. 29} & golpe rítmico & \\
\hline & & \multicolumn{2}{|c|}{ c. 31} & golpe rítmico & \\
\hline \multirow{4}{*}{ C } & \multirow{4}{*}{ c. $34-39$} & \multicolumn{2}{|c|}{ c. 34} & \multicolumn{2}{|l|}{$1^{\circ}$ arpejo } \\
\hline & & \multicolumn{2}{|c|}{ c. 36} & \multicolumn{2}{|l|}{$2^{\circ}$ arpejo } \\
\hline & & \multicolumn{2}{|c|}{ c. 38} & \multicolumn{2}{|l|}{$3^{\circ}$ arpejo } \\
\hline & & \multicolumn{2}{|c|}{ c. $39-40$} & \multicolumn{2}{|c|}{ gesto em silêncio } \\
\hline \multirow{3}{*}{ D } & \multirow{3}{*}{ c. $40-45$} & \multicolumn{2}{|c|}{ c. 40} & \multicolumn{2}{|c|}{ golpe rítmico } \\
\hline & & \multicolumn{2}{|c|}{ c. 43} & \multicolumn{2}{|c|}{ golpe rítmico } \\
\hline & & \multicolumn{2}{|c|}{ c. 44} & golpe rítmi & \\
\hline
\end{tabular}

Ex.1 - Tabela de seções e gestos musicais do Quadro nº 1 
Abaixo segue a descrição e hierarquização dos gestos musicais estabelecidos por CARDASSI (1998) e encontrados em Vastidão:

\begin{abstract}
1) Sonoridades Percussivas: gestos com alto índice de percussividade. Tanto timbre quanto ritmo são prioritários para a sua definição, enquanto altura e intensidade são secundários;

- Golpes Ritmicos: São formados basicamente por uma ou duas figuras curtas, freqüentemente acentuadas, seguidas de uma figura longa, associando este gesto a um caráter percussivo, nervoso, com intervalos de $2^{\text {a }}$ Menor e $3^{\text {a }}$ Menor.

2) Trilhas Melódicas: Configuram tanto fragmentos de linhas melódicas quanto motivos temáticos recorrentes. A sua função predominante é produzir momentos de relaxamento, em oposição à atmosfera de tumulto caracteristica dos sons móveis e sonoridades percussivas:

- Temas contrapontísticos: 0 que caracteriza estes gestos é o caráter improvisatório e leggero da linha melódica, que pode ocorrer em solo, com acompanhamento, ou em imitação. Assim, a palavra contrapontístico no nome deste gesto não implica necessariamente a ocorrência de contraponto, sendo apenas um indicativo da simultaneidade e do caráter improvisatório dessas linhas. Os temas contrapontisticos ocorrem freqüentemente associados a um tratamento ritmico em sincopas;

- Terça Menor: Constitui-se quase em um motivo temático, pela insistência com que se manifesta (...), e pela sua importância na configuração das demais trilhas melódicas.

3) Fragmentos Cortantes: Os fragmentos cortantes são gestos breves que provocam uma interrupção brusca do discurso musical e, como elemento surpresa, contribuem para a manutenção da atmosfera dramática;

- Interferências Angulares: Gestos caracterizados por intervenções muito breves, têm nivel elevado de intensidade e investem o trecho musical de um caráter agressivo.

- Gesto em Silêncio: Freqüentemente pausas como fermata, constituem um elemento de fragmentação do discurso; contribuem para o aumento do nivel de incerteza e de imprevisibilidade da música e resultam em eventos de alto teor dramático. (CARDASSI, 1998, p.42-74, passim)
\end{abstract}

0 material apresentado na seção A (Ex.2) envolve uma linha isolada finalizada por uma trilha melódica e dividida em quatro gestos musicais similares descritos como tema da chamada. Este gesto não se encontra na citação acima e será descrito logo a seguir.
Cunhada por Celso Loureiro CHAVES, a expressão tema da chamada refere-se a pequenos fragmentos melódicos "que pela sua concepção intervalar funcionam como verdadeiros 'pedidos de socorro', como verdadeiras 'chamadas" (CHAVES 1982, s/p). Encontrados inicialmente em Terra Selvagem (1971), tais fragmentos possuem configuração rítmica e intervalar semelhante aos gestos musicais referidos em Vastidão. Luciane CARDASSI afirma que,

o tema da chamada de Terra Selvagem, nos primeiros compassos da peça, que enfatiza o intervalo de terça menor e ocorre associado aos golpes ritmicos (sonoridades percussivas), exemplifica essa tendência das trilhas melódicas ao caráter épico, ao lirismo pungente, sem declinar de seu aspecto de suspensão (CARDASSI, 1998, p.107).

0 último dos temas da chamada em Vastidão estendese por uma trilha melódica contendo um golpe rítmico, o que constitui a mais clara similaridade existente entre a introdução de Vastidão e Terra Selvagem (ver Ex.3). Assim, a seção A de Vastidão se identifica com o caráter referido por CARDASSI.

As temáticas "terra", "vento" e "horizonte" discutidas por CARDASSI (1998) como recorrentes na obra de Bruno Kiefer vão ao encontro do título Vastidão na medida em que todos os quatro termos envolvem necessariamente a idéia de espaço. Esta aproximação e a admissão do compartilhamento de gestos musicais entre Terra Selvagem e o Quadro n'. 1 tornam inevitável a associação entre os títulos destas duas peças. Assim, a idéia de vastidão que Kiefer empregou aqui se afirma como referência à imensidão territorial. Poder-se-ia ainda inferir que este espaçamento é vinculado a uma delimitação geográfica na medida em que as temáticas "terra", "vento" e "horizonte" originam-se do poeta do pampa brasileiro, Carlos Nejar, e se transfiguram em música por Kiefer. 0 compositor, por sua vez, apesar de ter nascido na Alemanha e to-

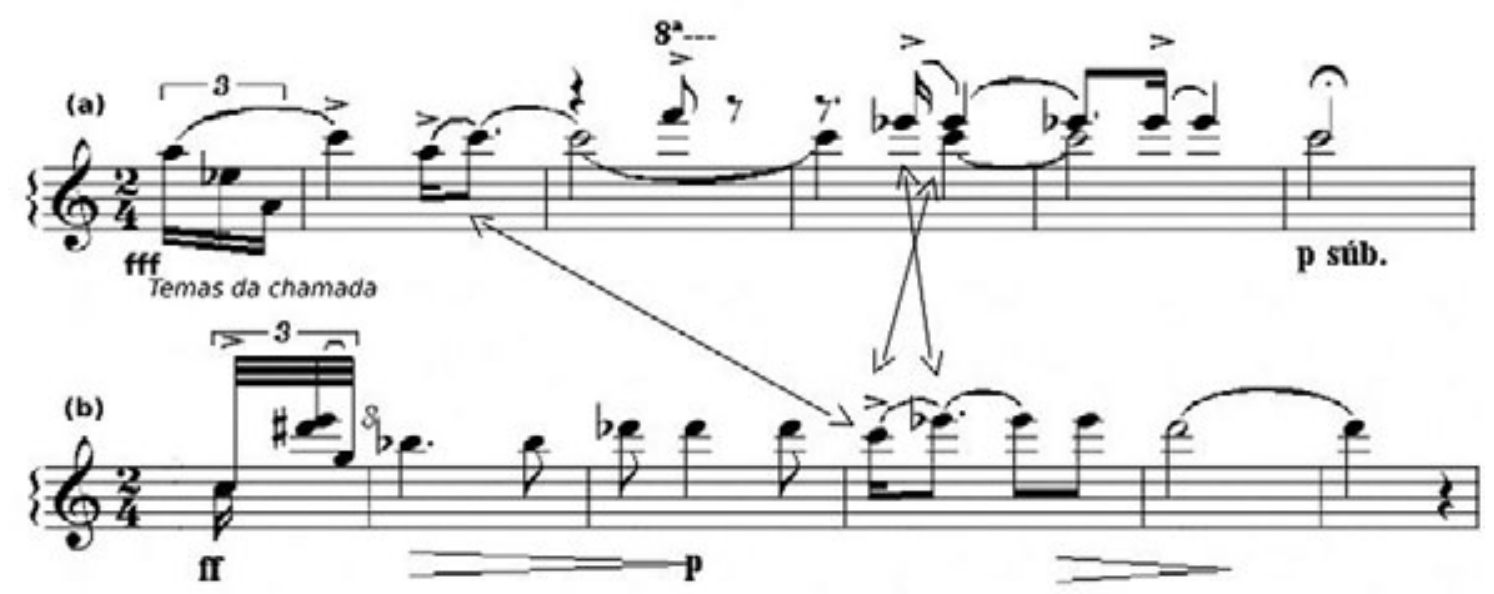

Ex.2 - Seção A de Vastidão (anacruse ao c.1-12) de Bruno Kiefer. 


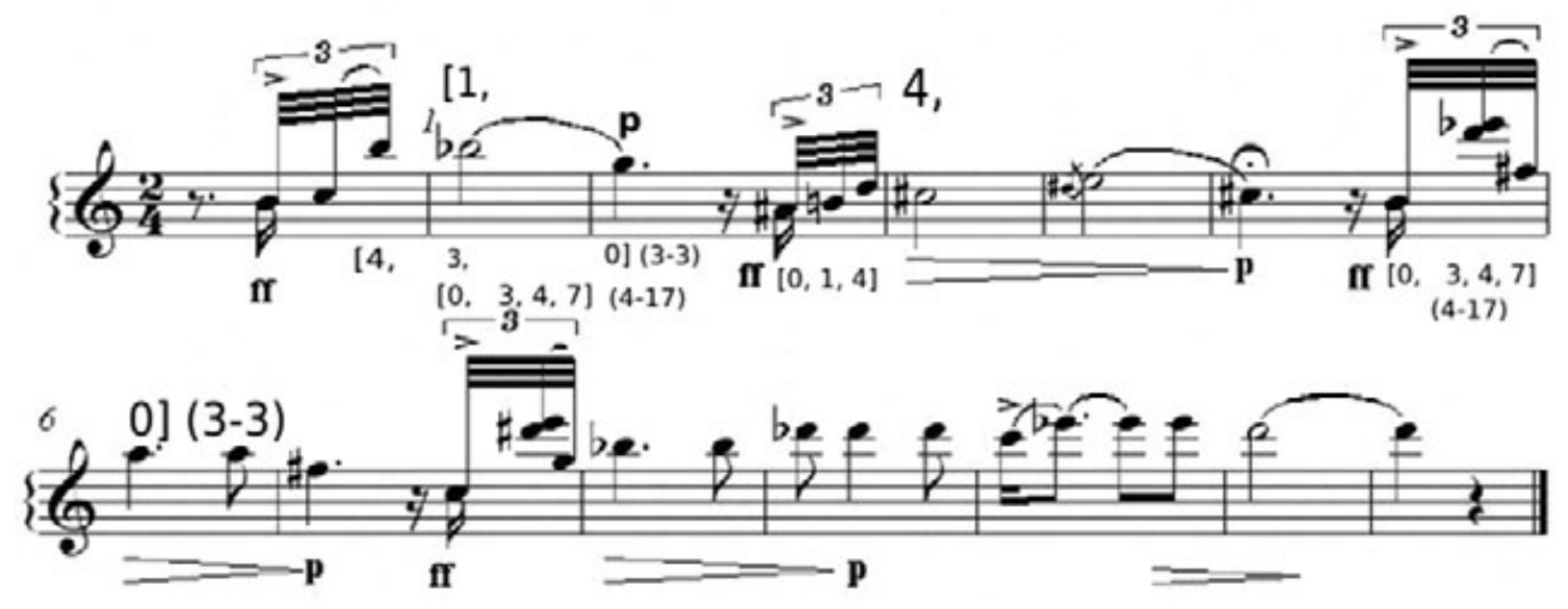

Ex.3 - (a) = Terra Selvagem (1971) de Bruno Kiefer - anacruse ao c.3-7;

(b) = Vastidão (1981) de Bruno Kiefer - anacruse ao c.8-12.
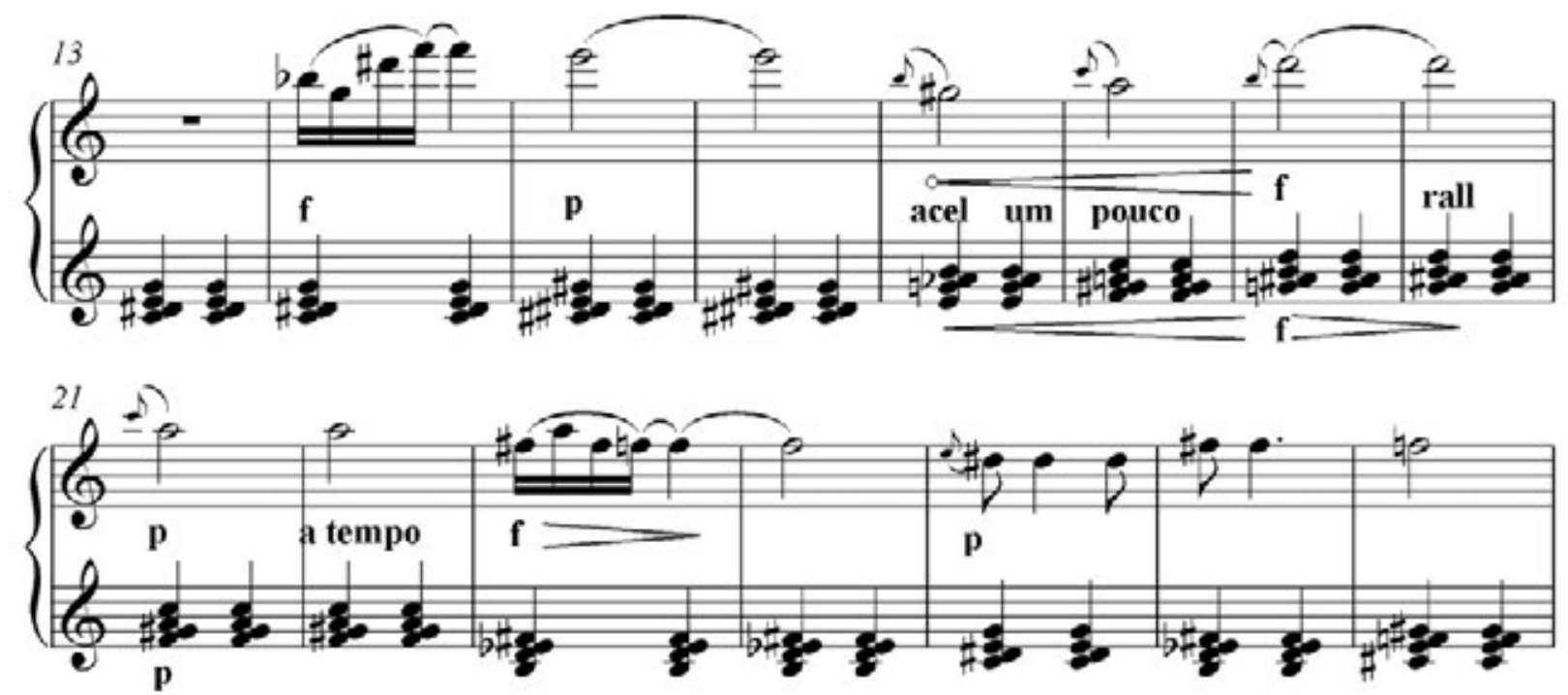

Ex.4 - Seção A de Vastidão (anacruse ao c.1-12) de Bruno Kiefer.

mado um caminho estético independente dos nacionalistas (com suas referências diretas ou indiretas ao folclore), ainda assim, se afirmou como compositor legitimamente brasileiro, tendo adotado a capital gaúcha como sua terra. A vastidão que intitula esta música é possivelmente aquela dos campos do extremo sul brasileiro, com pouca ou nula interferência do homem e uma dura realidade social. Os temas da chamada que abrem a peça fazem jus a este panorama com sua brusquidão e isolamento da linha melódica.

As notas longas polarizadas deste gesto ${ }^{4}$ são sucedidas por elaboração progressiva. Como o exposto no Ex.4, a primeira é apresentada como uma mínima (Sib, c.1), a segunda é repetida e ornamentada (Dó\#, c.3-5) e as últimas duas se repetem novamente no espaço temporal de uma mínima (Lá, c.6 e Sib, c.8), sendo a última desenvolvida pela trilha melódica.

0 conjunto de classes de alturas $[0,1,4]$ (3-3) que permeia internamente os temas da chamada tanto o faz em pares integrando o conjunto maior $[0,3,4,7](4-17)$, como se apresentando sozinho, de modo normal ou invertido $[4,3,0]$. Além disso, relaciona as notas polarizadas de cada gesto, como exposto através dos números em tipo maior do Ex.4, o que resulta na unidade interna e externa entre os gestos. Os intervalos de $2^{\text {a }}$ menor e $3^{a}$ menor, bem como suas respectivas inversões, são costurados ao longo de toda a seção A. As disposições intervalares aqui presentes resultam em elementos da coleção octatônica em contraste com conjuntos envolvendo cromatismos. 
Na seção B (c.13-33), a linha melódica permanece sendo agora acompanhada por uma sucessão regular de acordes na pauta inferior, os quais impõem estabilidade ritmica ao discurso. 0 Ex.5 apresenta este ostinato através de um trecho da seção $B$ :

Estes acordes não só acompanham a trilha melódica da pauta oposta, como ecoam as alturas que compõem tal trilha. Sua configuração intervalar, como na seção anterior, delineia o conjunto $[0,3,4,7](4-17)$, que apresenta, por sua vez, dois subconjuntos $[0,1,4](3-3)$ dispostos em espelho (Ex.5). ${ }^{5}$

Os temas contrapontísticos encontrados nos c. 14, 23 e 28 (vide Ex.8 à frente) ainda que se situem nos tempos fortes de cada compasso e não na anacruse, derivam do tema da chamada em função do contraste de movimentação rítmica que produzem. As inflexões de dinâmica e ritmo
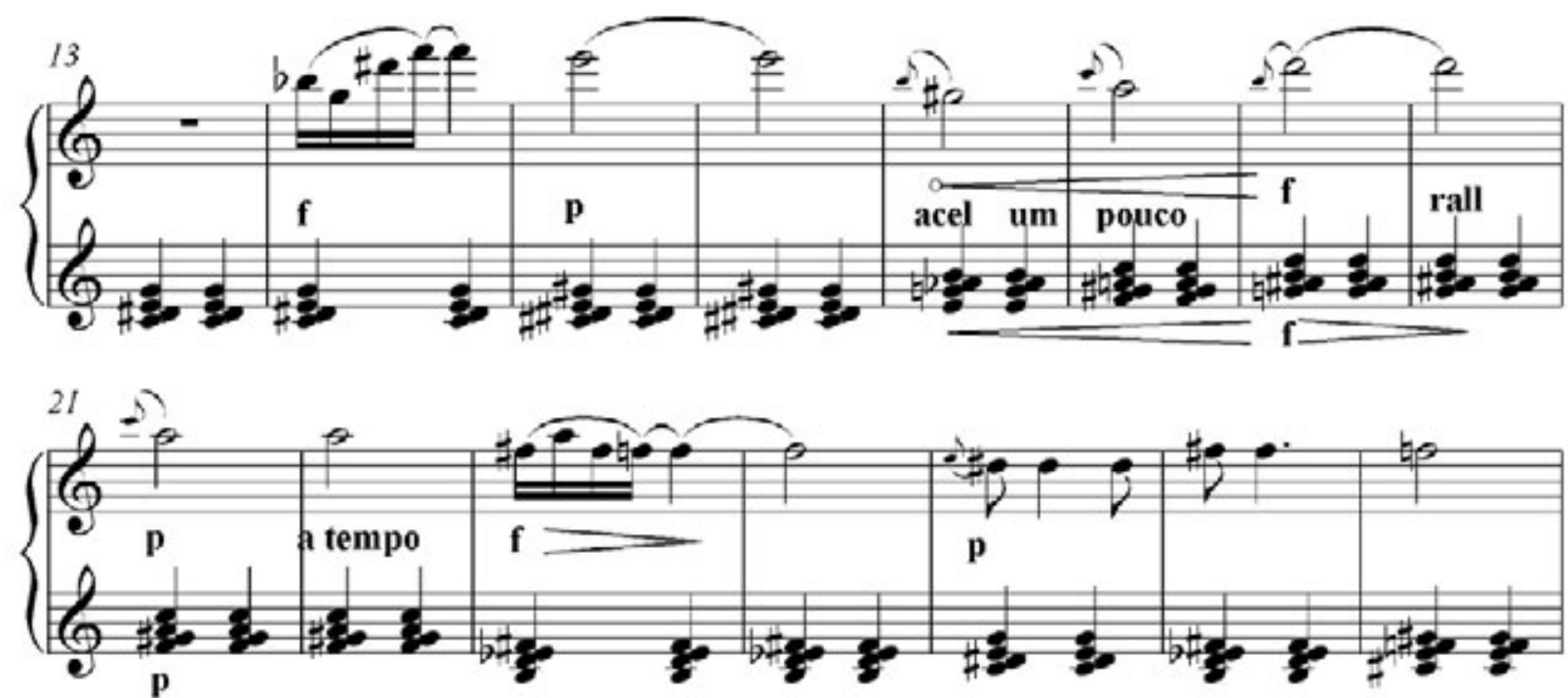

Ex.5 - Seção B de Vastidão: início (c.13-27).

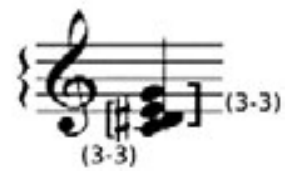

Ex.6 - Acorde em Espelho formando o conjunto (4-17), presente na seção B.

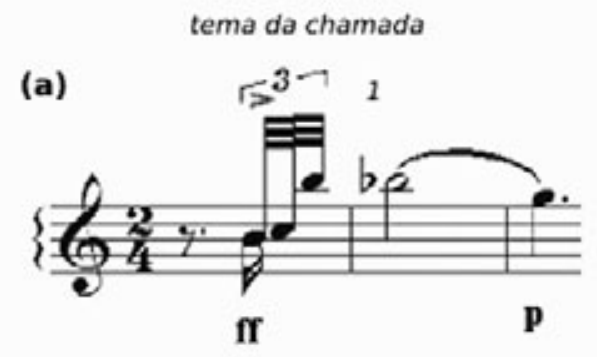

(b) tema contrapontistico

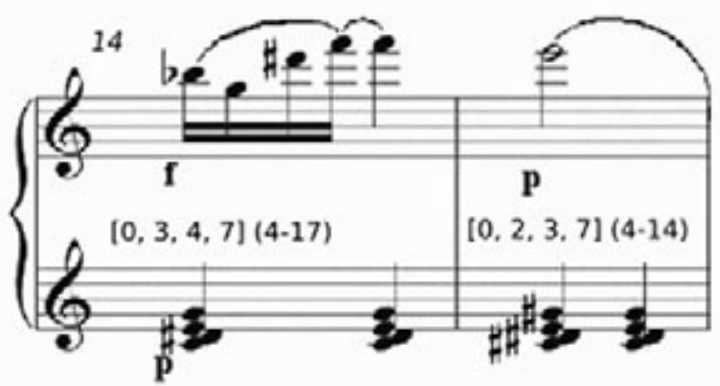

Ex.7 - (a), anacruse ao c.1;

(b), c.14-15. 
permanecem, porém de maneira diferenciada, pois as figuras rítmicas são mais lentas (com exceção do c. 28) e as indicações de dinâmica se suavizam. 0 Ex.7 compara estes dois gestos superficialmente similares:

Estas modificações gestuais, juntamente com a estabilidade da métrica e a estaticidade dos acordes da pauta inferior, configuram um caráter contrastante com 0 apresentado na seção anterior, pois contribuem para a projeção da trilha melódica que dá seguimento a este tema contrapontístico e se estende liricamente ao longo de toda seção B. No entanto, esta trilha não perde o "caráter agressivo" (CARDASSI, 1998, p.69) propiciado pelos golpes rítmicos (Ex.8d).

As duas trilhas melódicas desta peça possuem fortes traços de semelhança entre si, além da recorrência de parâmetros como altura, intervalos e ritmo. Os Ex.8a$8 \mathrm{~d}$ focalizam estas semelhanças (Ex.8a representando a $1^{\text {a }}$ trilha e os demais exemplos representando trechos da $2^{\text {a }}$ trilha):

Na segunda trilha melódica, observa-se o uso quase exclusivo da coleção octatônica a partir do c.17. Entre os c.17-27, esta disposição intervalar se apresenta de ma- neira completa. A única altura que não pertence a (828) é uma apojatura com a funcionalidade de ornamento ou nota de passagem no c.25. Como mostram os Ex.8c e Ex.8d, os c.29-33 apresentam o retorno parcial desta coleção com o uso das mesmas alturas aplicadas nos c.17-19. 0 tema contrapontístico do c.28 constitui mais uma vez o conjunto $[0,3,4,7](4-17)$, o qual também é um subconjunto da coleção octatônica.

A seção $\mathbf{C}$ vem ocupar o papel de digressão no discurso musical, sendo a seção mais contrastante de todo o Quadro n. 1. Aqui o acúmulo vertical dos sons toma o primeiro plano, ocupado anteriormente pela métrica. Seus três arpejos configuram uma idéia musi$\mathrm{cal}^{6}$ categorizada por CARDASSI (1998, p.140) como configuradora de "um processo de autocitação", pois ocorre em várias outras obras do compositor. A função desta idéia é "de elemento fragmentador do discurso musical, atuando como uma perturbação do material musical lírico elaborado nesses trechos" (ibid, p.154). Em Vastidão tal idéia apresenta as sonoridades que se situam nos registros extremos da peça. As pausas que separam seus arpejos aumentam a cada intervenção, e assim configuram um aspecto fragmentário, como demonstrado no Ex.9:

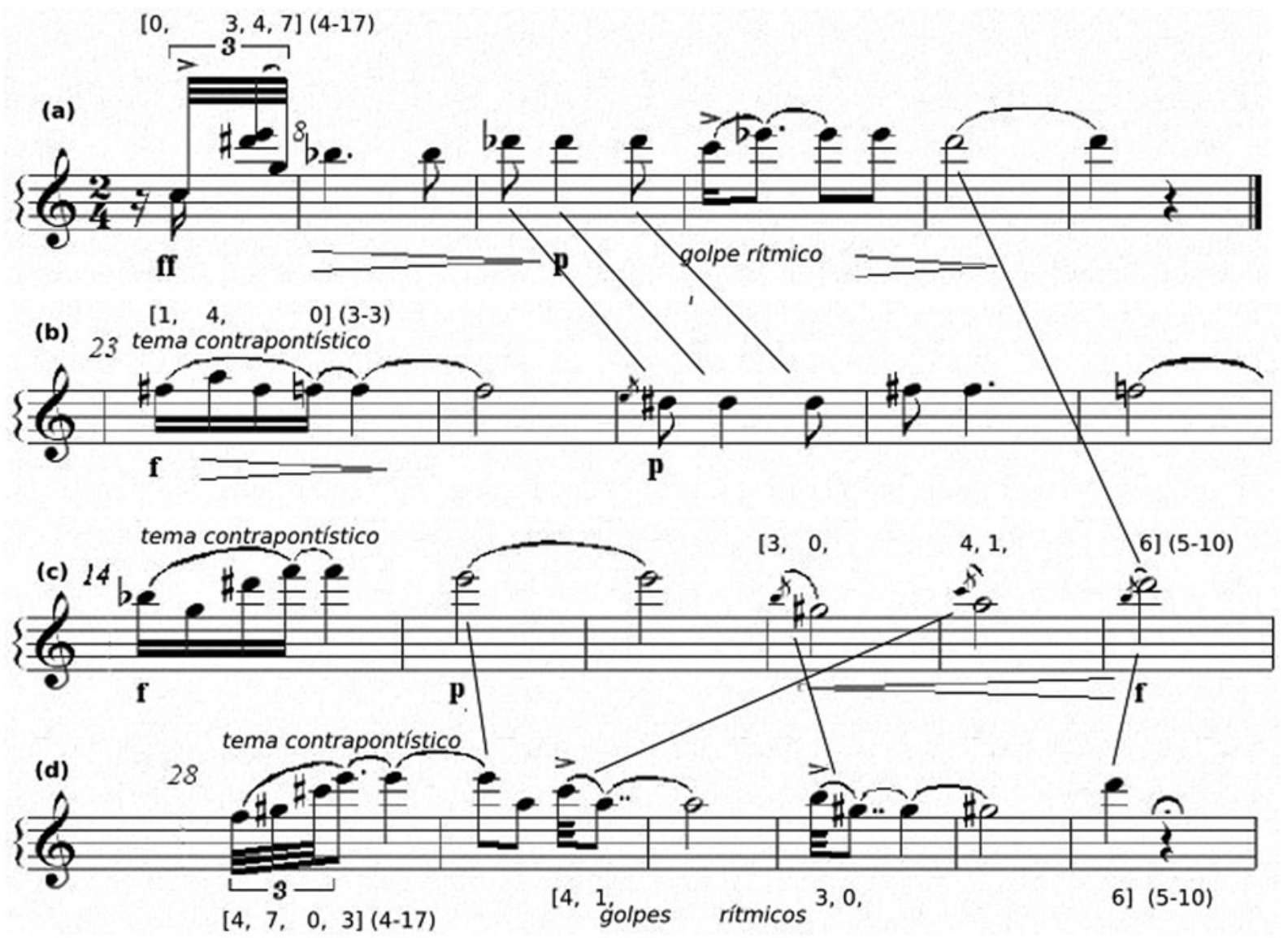

Ex.8 (a) = anacruse ao c.8-12: $1^{\text {a }}$ trilha $($ seção $A) ;(b)=c .23-27: 2^{\text {a }}$ trilha $($ seção $B) ; \quad(c)=$ c.14-19: $2^{\text {a }}$ trilha (seção B); (d) = c.28-33: $2^{\text {a }}$ trilha (seção B). 


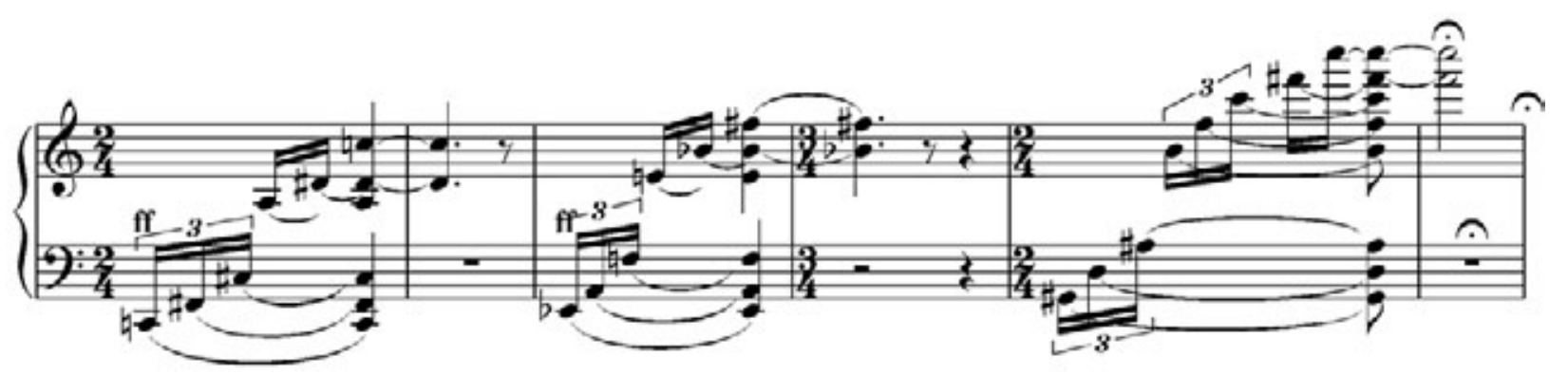

Ex.9 - Arpejos (Seção C - c. 34-39).

(a)

(b)
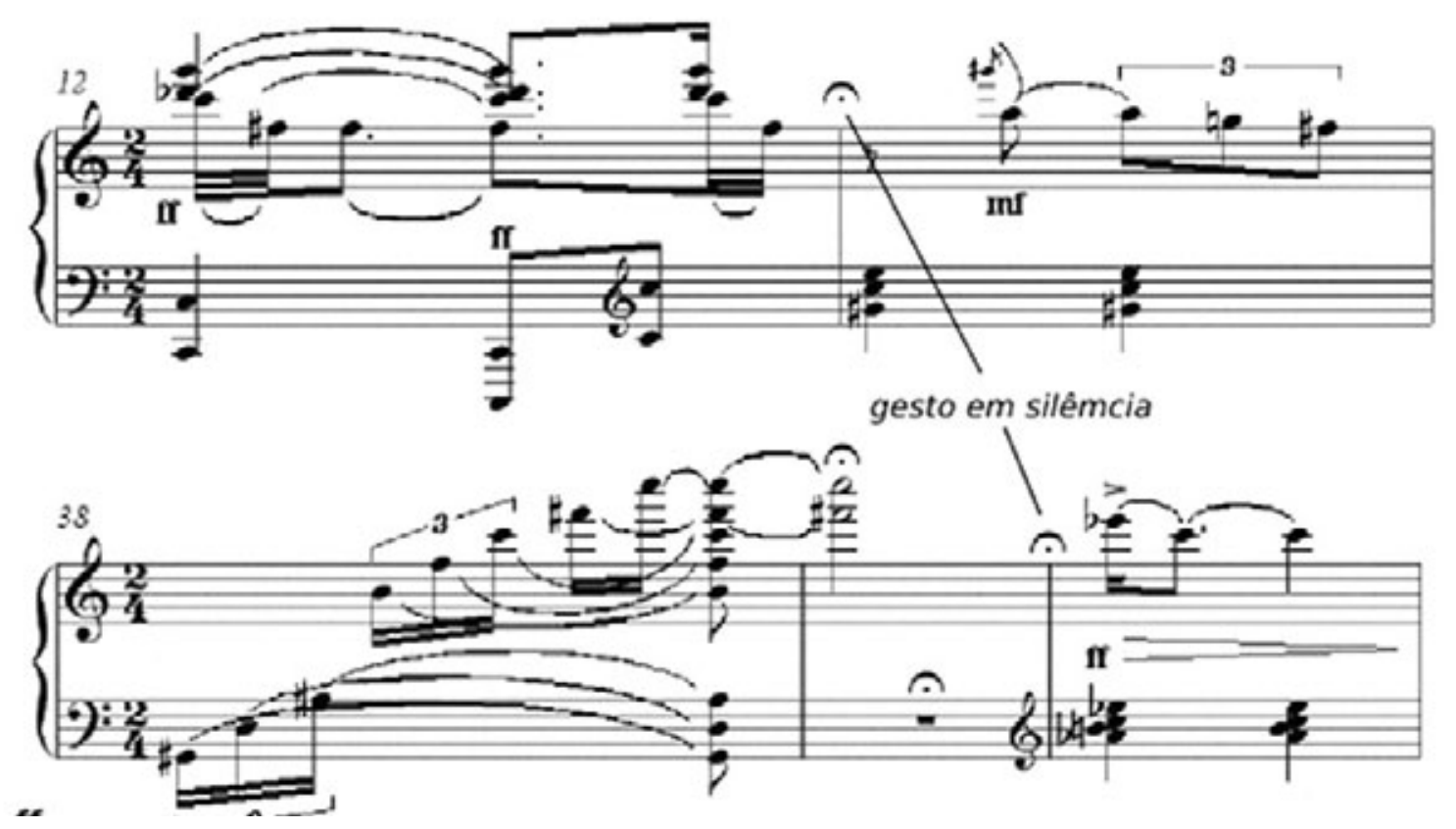

Ex.10 - (a) = Tríptico n ${ }^{\circ} .1$ (1969) de Bruno Kiefer (c.12-13);

(b) = Quadro n. 1, Vastidão (1981) de Bruno Kiefer (c.38-40).

Por outro lado, mesmo que a seção $\mathbf{C}$ seja internamente fragmentada, possui traços em comum com a seção A. Estão presentes a seqüência de gestos similares, a ausência de ataques simultâneos e a diminuição da intensidade de um determinado parâmetro musical constatada distintamente em cada seção: nos arpejos ocorre a diminuição de textura, enquanto que nos temas da chamada, a diminuição é de dinâmica. Além disso, o aumento do número de classes de alturas contribuindo para o desenvolvimento do texto musical é encontrado em ambas as seções.

Não obstante ao contraste de caráter acarretado pela seção $\mathbf{C}$, seu primeiro arpejo sucede a seção anterior preservando as mesmas relações intervalares. Trata-se do conjunto (5-31), outro fragmento da coleção octatônica. 0 segundo arpejo tende ao cromatismo e o último apro- xima-se novamente da escala octatônica. 0 subconjunto (3-3) apresenta-se em um número crescente de ocorrências em cada arpejo, culminando no último (c.38) onde as três versões deste subconjunto são protagonizadas por todas as notas do gesto.

Dentre os vários fatores que ocupam lugar na genealogia de Vastidão, encontra-se o gesto em silêncio, constituído pela fermata entre os c.39-40 (ver Ex.10a). Esta pausa, separando uma estrutura em ff de uma melodia acompanhada por acordes, remonta à obra Tríptico (1969) de Bruno Kiefer. ALBUQUERQUE (1972, p.5), referindo-se à fermata localizada entre os c.12-13 do $1^{\circ}$ Tríptico, carrega este elemento de um "sentido de expectativa". Pode-se referir da mesma maneira ao gesto em questão, dado o fato de que o terceiro arpejo de Vastidão atinge o Dó mais agudo da peça, em um registro não explorado até então: 


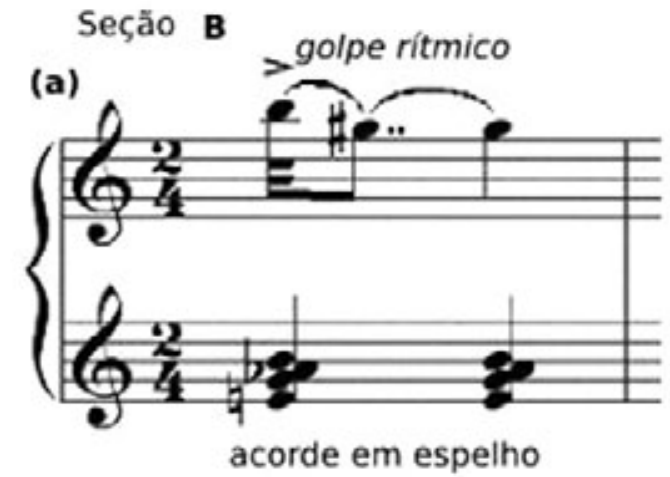

Ex.11 - (a) = Seção B de Vastidão: c.31;

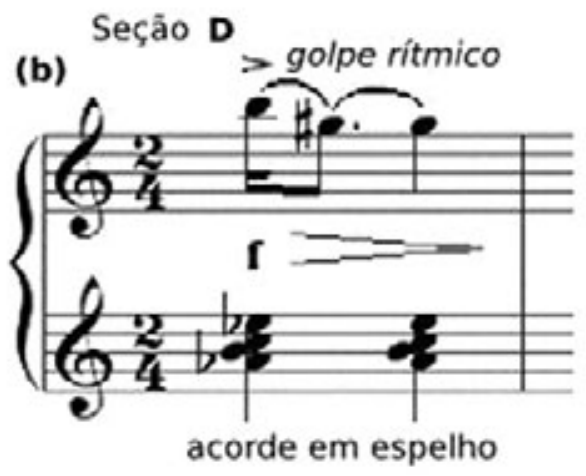

(b) = Seção D de Vastidão: c.43.

A seção D prenuncia o final da peça com uma métrica que tende a estaticidade devido à quebra do fluxo rítmico do material da pauta inferior (c.41-42). Esta paralisação evidencia a distância temporal entre os primeiros dois golpes rítmicos (pauta superior, c.40 e c.43), causando com isto um efeito de fragmentação típico da estética de Kiefer. No entanto, a unidade estrutural é reforçada pela economia de materiais: recapitulando o material harmônico e textural utilizado na seção $B$, são empregados não apenas os mesmos intervalos, mas as mesmas classes de alturas, as quais se inserem em acordes em espelho e golpes rítmicos distribuidos entre as duas pautas (Ex.11):

\section{3 - Conclusão}

Em Vastidão a 2a menor e a $3^{\text {a }}$ menor são os intervalos mais presentes, constituindo alicerces da estrutura da peça na medida em que Kiefer constrói os subconjuntos [0, 1, 4] (33) e $[0,3,4]$ - a inversão de (3-3). Estes conjuntos são comumente encontrados juntos dando forma aos acordes de acompanhamento da seção $B,[0,3,4,7](4-17)$ e em alguns fragmentos. Este último, um superconjunto, assim como 0 $1^{\circ}$ arpejo da seção $\mathbf{C}$, constituído por (5-31) são fragmentos da coleção octatônica. 0 compositor fez uso abundante da configuração intervalar destes acordes de acompanhamento, imprimindo à peça um conteúdo harmônico essencialmente octatônico com toques de cromatismos, fato este que vai ao encontro dos apontamentos de Gerling (2001), sobre as peças Terra Selvagem (1971), Lamentos da Terra (1974) e Alternâncias (1984).

Quanto à estrutura gestual, Vastidão apresenta traços de semelhança, através dos temas da chamada, com Em Poucas Notas (1974) e Terra Selvagem (1971), além de trilhas melódicas com gestos internos muito comuns na escrita do compositor. Presume-se por sua riqueza gestual, única no conjunto dos Seis Pequenos Quadros (1981) que esta epígrafe sintetiza os aspectos mais marcantes da obra pianistica de Kiefer.

\section{Referências}

ALBUQUERQUE, Armando. Apresentação e Análise dos Movimentos. In: Tríptico (piano - 1969). Editora da Ufrgs. Porto Alegre. Cadernos de música/1, 1972. 1 partitura.

CARDASSI, Luciane. A música de Bruno Kiefer: "terra", "vento", "horizonte" e a poesia de Carlos Nejar. Dissertação - Mestrado - UFRGS-PPGMUS. Porto Alegre. 1998.

CHAVES, Celso Loureiro: Apresentação. In. Terra Selvagem. Editora da Universidade. Cadernos de música/3. Porto Alegre. 1982.

FORTE, Allen. The Structure of Atonal Music. New Haven. Yale University press, 1973.

GERLING, Cristina C.. Traços característicos na música para piano de Bruno Kiefer. Opus. v. 3 n. 3, p. 75-80. Porto Alegre. set. 1991.

'Terra Selvagem', 'Lamentos da Terra' e 'Alternâncias': o componente octatônico nas últimas três peças para piano de Bruno Kiefer. In: PER MUSI. v. 4, p. 52 - 71, Belo Horizonte. 2001.

LAITANO, Yanto \& GERLING, Cristina. Análise da música "Em Poucas Notas..." de Bruno Kiefer segundo a Teoria dos Conjuntos de Allen Forte. Disponivel em: http://www.ex-machina.mus.br/welcome.htm. Acesso em: 28 out. 2008.

PERSICHETTI, Vincent. Twentieth-Century Harmony. New York, Norton \& Company, Inc.1961. 


\section{Partituras}

KIEFER, Bruno. Seis Pequenos Quadros. Partituras para piano manuscritas em duas cópias: à lápis; à nanquim em papel vegetal, Acervo particular de Nídia Kiefer, Porto Alegre - 1981.

sica/3, 1982.

Terra Selvagem. Partitura para piano - 1971. Editora da Universidade. Porto Alegre, Cadernos de mú-

Tríptico. Partitura para piano - 1969. Editora da Ufrgs. Porto Alegre. Cadernos de música/1, 1972.

\section{Leitura recomendada}

STRAUS, Joseph N. Introduction to Post-Tonal Music. New Jersey: Prentice Hall, Inc, 2000.

\section{Notas}

1 A pesquisa realizada resultou na dissertação de Mestrado de Germano Mayer, orientada pela Dra. Any Raquel CarvaIho e defendida em setembro de 2005, sob o titulo: "Seis Pequenos Quadros (1981) de Bruno Kiefer: relações intervalares e outros parâmetros a partir da teoria dos conjuntos e gestos musicais".

2 CARDASSI entende gesto musical como "um conjunto de sons (ou signos) que compõe uma unidade fundamental e recorrente. Cada gesto apresenta determinadas características peculiares nos quatro parâmetros musicais básicos (altura, intensidade, duração e timbre), as quais devem ser suficientes para sua identificação pelo analista e pelo ouvinte" (CARDASSI, 1998, p.7).

3 Em análise realizada das peças Terra Selvagem (1971), Lamentos da Terra (1974) e Alternâncias (1984), GERLING já havia averiguado "a presença de sonoridades recorrentes cuja conformação coincide com o conteúdo intervalar das coleções octatônicas" (GERLING, 2001, p.52).

4 LAITANO \& GERLING afirmam que na peça Em poucas notas (1974), também de Bruno Kiefer, o tema da chamada, "sempre é usado de modo a criar um pólo momentâneo em uma determinada nota". Trata-se da atração exercida pela nota longa imediatamente posterior às fusas, que faz com que estas últimas "corram" em sua direção constituindo uma polarização. (disponivel em http://www.ex-machina.mus.br/welcome.htm)

5 De acordo com PERSICHETTI, "qualquer acorde (de duas, três, quatro notas, policorde ou composto) pode ser espelhado através da adição dos intervalos da formação original estritamente invertidos" (1961, p.172). Neste caso, o acorde em questão é o conjunto (3-3), e o intervalo de $2^{\text {a }}$ menor é o pivô desta formação.

6 CARDASSI afirma que a expressão "idéia musical deve ser entendida como a somatória do gesto musical com o contexto em que esse gesto ocorre e a função desempenhada por ele, configurando trechos musicais de diferentes dimensões" (1998, p.140).

Germano Gastal Mayer é Bacharel em música (2003) e Mestre em práticas interpretativas (2005) pela Universidade Federal do Rio Grande do Sul com bolsa da CAPES. Foi professor substituto da Universidade Federal de Pelotas (20052007), professor colaborador na Escola de Música e Belas Artes do Paraná (2007), e pianista instrutor da Escola do Teatro Bolshoi no Brasil (2008). Paralelamente a estas atividades, tem atuado como pianista camerista e solista no sul do país. Desde o início de 2009, é membro do quadro efetivo de professores do Conservatório de Música da UFPEL, onde leciona piano e matérias teóricas.

Any Raquel Carvalho é Doutora em Música e Mestre em Música pela University of Georgia (Athens, Georgia, USA). É Professora Associada no Programa de Pós-graduação em Música e no Departamento de Música do Instituto de Artes da Universidade Federal do Rio Grande do Sul (UFRGS), onde leciona órgão, contraponto e fuga. Atua como conferencista e organista no Brasil e no exterior. Possui dois livros publicados sobre contraponto: Manual de Contraponto Modal (Editora Evangraf, 2a ed., 2006) e Manual de Contraponto Tonal e Fuga (Editora Novak Multimidia, 2002). Como pesquisadora do CNPq, desenvolve trabalhos na área de práticas interpretativas, incluindo música brasileira para órgão e contraponto. 